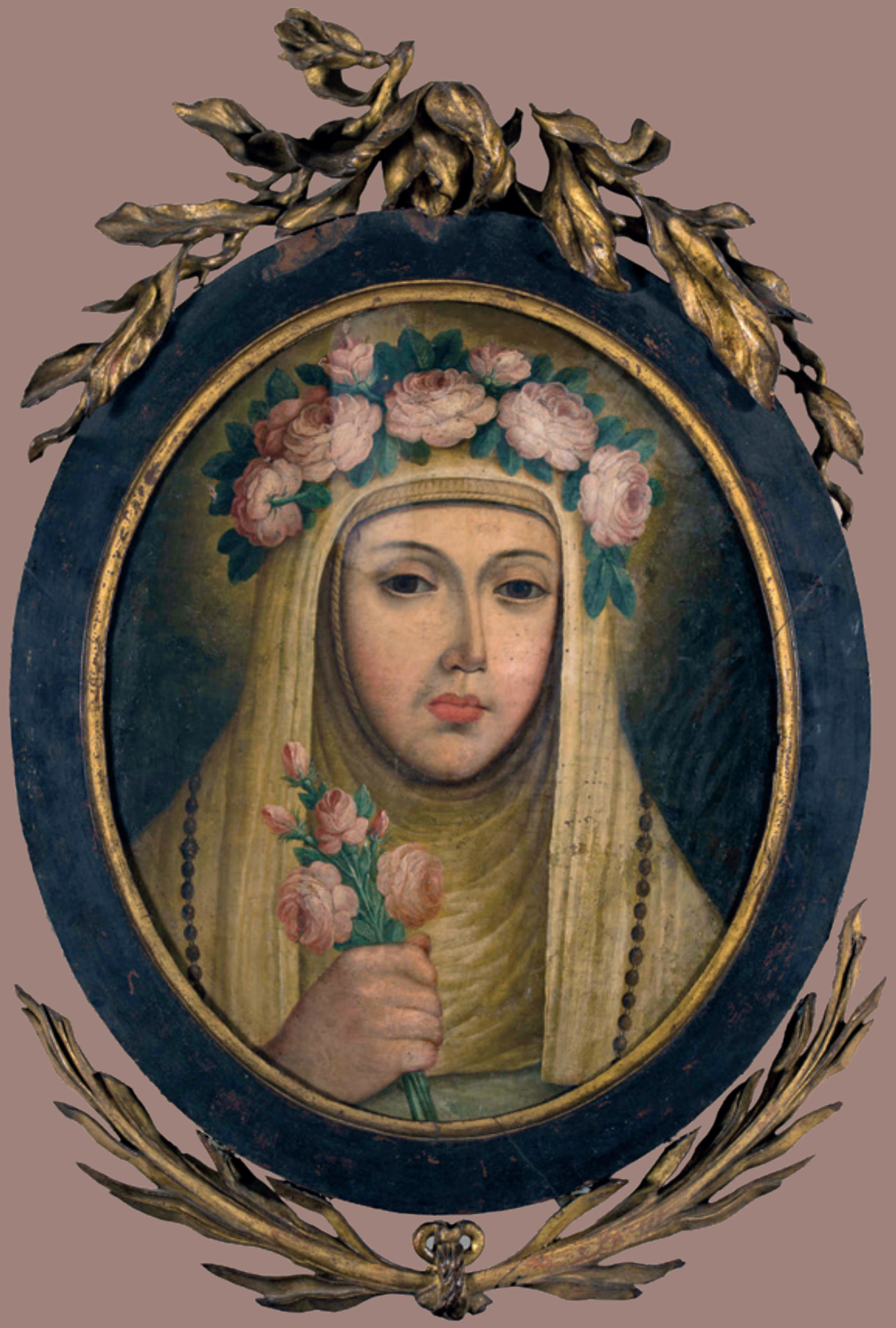

Pedro Díaz. Retrato de Santa Rosa de Lima. Óleo sobre tela, 44 x 66 cm, 1804. Museo Convento San Francisco de Lima. 


\title{
Un retrato de Santa Rosa de Lima firmado por el pintor Pedro Díaz ${ }^{1}$
}

\author{
Anthony Holguín Valdez \\ Universidad Nacional Mayor de San Marcos \\ anthony_92_63@hotmail.com \\ Lima - Perú
}

\begin{abstract}
Resumen
El Museo y Convento San Francisco de Lima conserva en su pinacoteca un retrato ovalado de Santa Rosa de Lima, obra firmada por el pintor Pedro Díaz. Damos a conocer esta pintura realizada por encargo del canónigo catedralicio José Joaquín de Uztáriz en 1804, obra inédita que nos aproxima a la trayectoria artística del pintor limeño y su importante producción pictórica en la escena local.
\end{abstract}

Palabras clave: pintura, Santa Rosa de Lima, Pedro Díaz, José Joaquín de Uztáriz, convento de San

Francisco.

\begin{abstract}
The San Francisco de Lima Museum and Convent conserves in its art gallery an oval portrait of Santa Rosa de Lima, a work signed by the painter Pedro Díaz. We present this painting commissioned by Canon José Joaquín de Uztáriz in 1804, an unpublished work that brings us closer to the artistic trajectory of the Lima painter and his important pictorial production in the local scene.
\end{abstract}

Keywords: painting, Santa Rosa de Lima, Pedro Díaz, José Joaquín de Uztáriz, San Francisco

Convent

Son pocas las noticias documentales que se tienen sobre Pedro Díaz, una de las primeras referencias, es la de su participación como testigo en la boda del pintor Julián Jayo con María Caballero, en diciembre de 1771 (Esquivel, 2015, p.67). De esta manera sabemos que a partir de esta fecha, el pintor estuvo activo en el oficio de la pintura, logrando ejecutar un considerable corpus de obras tanto en el género religioso como en el retrato. En efecto, Díaz destacó como retratista ${ }^{2}$ para la galería de virreyes del Perú, siendo su primera efigie cortesana la del virrey don Manuel de Amat y Junyent, en cuyo lienzo firmó en 1773 como "Pedro José Díaz" (Fig.1), mientras que el último retrato institucional que realizó fue para el virrey Fernando de Abascal y Sousa en 1807; este trabajo no fue hecho de manera exclusiva para el Palacio Virreinal, tenemos noticias que Díaz realizó un retrato del virrey Francisco Gil de Taboada para la sala del Tribunal de la Real Renta de Tabacos, proyectado para el mes de julio de 1793, como indica un documento dirigido al contador del Tribunal:

1 El presente artículo fue presentado en el Primer Encuentro de Cultura Virreinal: Identidades limeñas a través de la interdisciplinariedad. Realizado en el Museo Convento San Francisco y Catacumbas de Lima, abril de 2019.

2 Su primer retrato firmado es del obispo Juan José Priego y Caro (1772), conservado en la iglesia de Santo Domingo de Arequipa. 


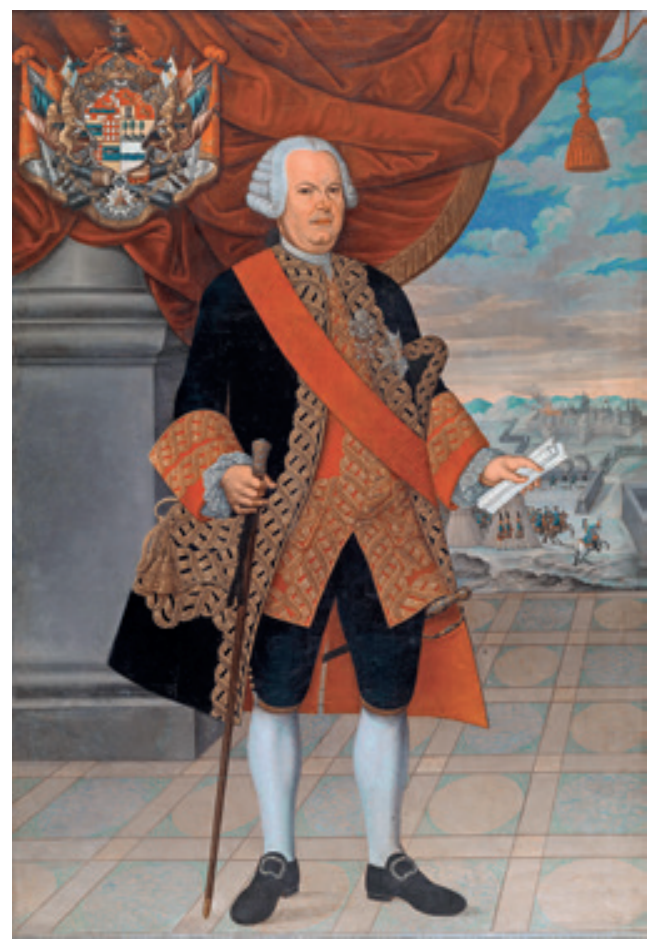

Fig. 1. Pedro Díaz. El virrey Don Manuel de Amat y Junyent. Óleo sobre tela, $201 \times 136,5 \mathrm{~cm}, 1773$. Museo Nacional de Arte de Cataluña. Fuente: www.museunacional.cat.

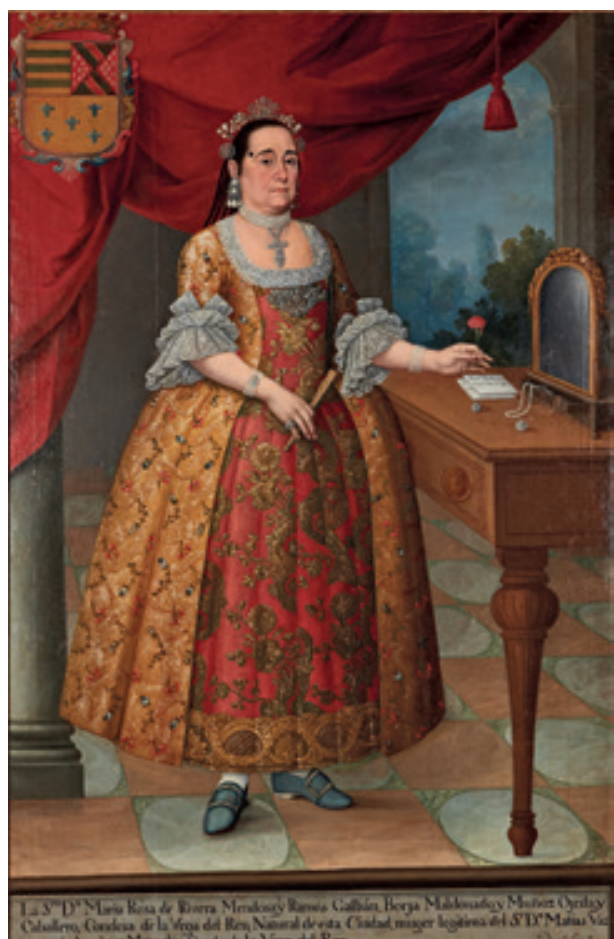

Fig. 2. Pedro Díaz. María Rosa de Rivera, Condesa de la Vega del Ren. Óleo sobre tela, sin medidas disponibles, 198 x $132 \mathrm{~cm}$, ca. 1788 . Colección Thoma Foundation, Estados Unidos. Fotografía: Collection of Carl \& Marilynn Thoma.

"me informado del estilo y practica que se ha observado anteriormente para executar [el retrato del virrey]" (AGN, 1793, f. 3r). En efecto, esto refiere a la serie de retratos de virreyes que conservó dicha institución, y que Pedro Díaz debió seguir las órdenes y gusto del "estilo" conservado en el Tribunal.

En junio de 1788, la Junta de Temporalidades convoca a Pedro Díaz para tasar un cuadro de San Gregorio Nacianceno, expropiado de la Compañía de Jesús del Cusco, pero el pintor se encontraba ausente en la ciudad según consta en un expediente de la época: "se me notició por un vecino platero frente de la casa donde vivió el dicho Don Pedro, que este se halla en el pueblo de Chincha cerca de dos años" (AGN, 1788, ff. 9v y 10r). Esto respondería ciertamente a que Díaz se trasladase al Sur con motivo de una demanda de retratos de la aristocracia terrateniente, ello si se considera que entre 1761 y 1795 la Corona Española concedió ciento cincuenta y dos títulos nobiliarios a otros tantos vecinos de Lima, según Flores Galindo, es una cifra que no admite comparación con ningún otro virreinato americano ni con ninguna época anterior de la historia del Perú (1984, pp.73-77). En este contexto Díaz, debió producir un importante corpus de retratos de la aristocracia costeña que son quizá lo menos conocido de su producción. Los ejemplares son diversos, pero citaremos algunos de los lienzos como el de Juana de Rivera y Herboso 3 (Ca. 1795-1810, Museo de Arte de Lima); María Rosa de Rivera, Condesa de la Vega del Ren (Ca. 1788, Colección Carl

3 Este retrato perteneció a una colección familiar de la ciudad de Pisco. Agradezco la información al investigador Ricardo Kusunoki. 
\& Marilynn Thoma Art Foundation) (Fig. 2); y Catalina Sánchez Boquete y Román de Aulestía (Colección Manuel Gastañeta Carrillo de Albornoz, Lima).

La actividad de pintor no fue la única fuente de ingreso que tuvo el artista. A principios de 1790 (Wuffarden, 2014, p. 382), ${ }^{4}$ se descubren nuevas vetas de azogue (mercurio) en Cerro de Pasco, importante producto mineral para el procesamiento de la plata, situación que lo llevó a ingresar en el negocio de la distribución de efectos de Castilla para la región minera, y en la que permaneció durante corto tiempo, sus obligaciones efectuadas con otros comerciantes capitalinos entre los años de 1793 y 1794 constan en protocolos notariales (AGN, 1794, ff. 326v, 447r, 568v), ${ }^{5}$ en estos documentos el pintor firma como "Josef Díaz de Mendoza” y alega su dominio del latín por las diversas citas que en ellos incluye. Asimismo, sabemos que otros artistas del periodo como el vasco Matías Maestro, participaron en este comercio, cuyo testimonio conocemos a través de diversas obligaciones y poderes notariales, inclusive la serie de dibujos que realizó de la mina de Pucayaco, en Cerro de Pasco. ${ }^{6}$

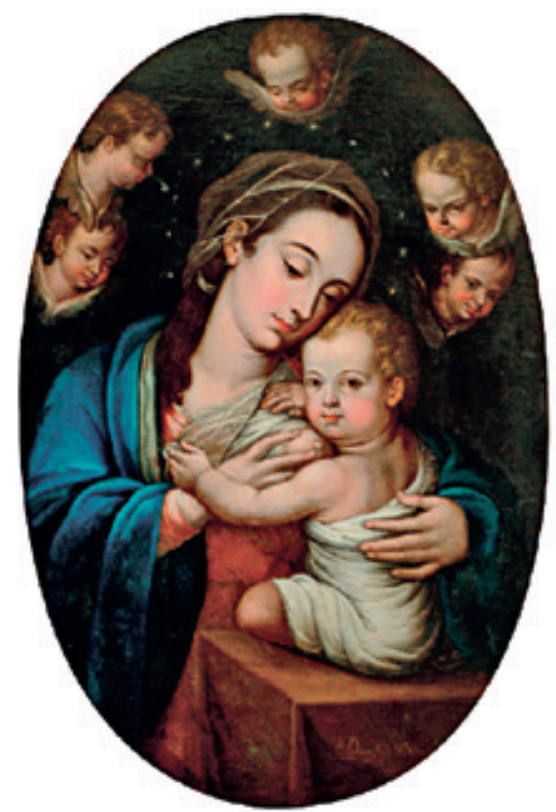

Fig. 3. Pedro Díaz. La Virgen de la Leche, según modelo de Mateo Pérez de Alesio. Óleo sobre tela, sin medidas disponibles, 1806.

Colección particular de Lima. Fuente: Kusunoki \& Wuffarden, 2014, p. 37.

El género de la pintura religiosa, en particular de las las imágenes devocionales, ${ }^{7}$ (Alcalá, 2014, p. 42) son una constante en la obra de Pedro Díaz. Sus primeras obras sobre este género son las que realizó para el convento mercedario de Lima: Santa Cecilia, David tocando el arpa y San Pedro Nolasco. En 1805, Vicente Parada y Pinzón, mayordomo de la cofradía limeña de la Virgen del Rosario de Chiquinquira, encarga al sevillano José del Pozo realizar el lienzo titular de la institución, pero el incumplimiento del pintor conllevó a trasladar el encargo a Pedro Díaz. Por otra parte, es posible identificar otros tantos lienzos que formaron parte en algún momento del ajuar familiar limeño, citaremos dos ejemplos: Virgen del Carmen con el Niño Jesús (1801, Museo de Arte de Lima); y la Virgen de la Leche, según modelo de Mateo Pérez de Alesio (1806, colección particular de Lima) (Fig. 3). La última noticia que tenemos sobre el pintor es cuando participa junto al sevillano José del Pozo en la decoración del nuevo retablo de la iglesia del Sagrario, esto en el mes de octubre de 1815, y a partir de los recibos de pago sabemos que Pozo recibe 1,767 pesos por el gran lienzo apoteósico del altar, y Pedro Díaz obtiene 414 pesos por la pintura del camarín ubicado detrás del retablo (AGN, 1815, fol.6v y 7r). Luego de este trabajo no tenemos información documental que justifique su presencia en otros encargos o su deceso en la ciudad.

4 Un año antes, en 1789, Pedro Díaz junto a otros pintores de Lima se presentaron ante el Cabildo Metropolitano para solicitar la exclusividad con respecto a la valorización de obras artísticas, que en ese momento había sido absorbida por tasadores de otro tipo de bienes.

5 La identificación de Pedro Díaz se ha realizado a partir del cotejo de las rúbricas presentes en los folios notariales y cartas de pago de pinturas que realizó en estas fechas.

6 El Archivo General de Indias de Sevilla conserva dos dibujos de las minas de Pucayaco de Matías Maestro, estas se pueden fechar entre 1790 y 1792 , años que corresponden a la actividad comercial del vitoriano y en el que tuvo importantes vínculos con mercaderes de Lima y Cerro de Pasco.

7 La imagen devocional es la que ayuda a la oración y provoca una respuesta emotiva. Son por lo general cuadros no narrativos de tamaño medio-pequeño y en los que aparece una sola figura. 


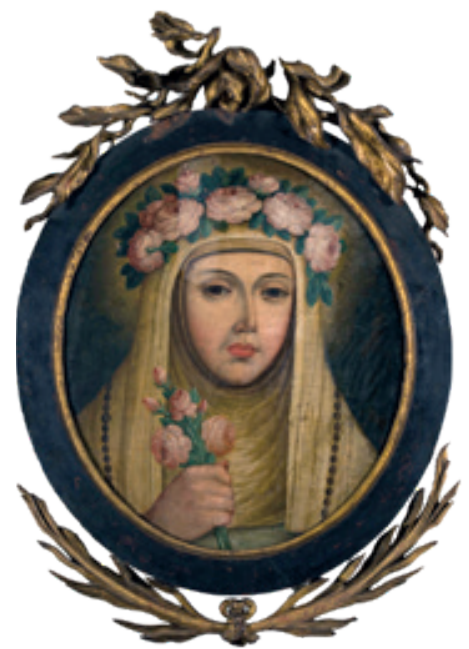

Fig. 4. Pedro Díaz. Retrato de Santa Rosa de Lima. Óleo sobre tela, 44 x $66 \mathrm{~cm}$., 1804. Museo Convento San Francisco de Lima. Fotografía: Museo Convento San Francisco de Lima.

\section{El retrato de Santa Rosa de Lima}

La pintura que presentamos a continuación, es una obra inédita de Pedro Díaz. Se trata del retrato de Santa Rosa de Lima (Fig. 4) que actualmente se conserva en una de las celdas del claustro principal del ahora Museo y Convento de San Francisco de Lima, y cuya difusión en importantes publicaciones impresas, le han atribuido fecha inexacta y autoría anónima (Flores Araoz, J. 1995, p. 230). En un primer acercamiento con el lienzo, identificamos que el pintor colocó una inscripción sobre el reverso de la tela. En la primera línea de la inscripción se lee: "A devoción de D. Josef Joaqn. Uztariz", en ella se ha identificado la compresión del nombre completo José Joaquín Uztáriz; mientras que en la segunda línea está escrito: "Pinto en Lima D. Pedro Diaz 1804". Por lo tanto, el pintor como de costumbre firma el lugar (ciudad de Lima) y fecha (año de ejecución), pero esta vez omite la escritura latinizada que es una constante en la mayoría de sus rúbricas (Fig. 5).

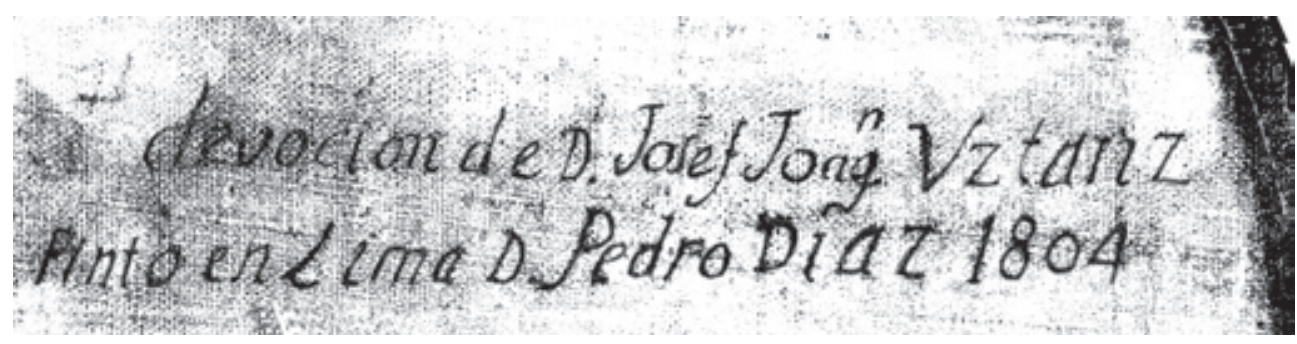

Fig. 5. Pedro Díaz. Retrato de Santa Rosa de Lima (detalle de la inscripción del reverso del lienzo). Tinta china sobre tela. Museo Convento San Francisco de Lima. Digitalizado: Anthony Holguín Valdez.

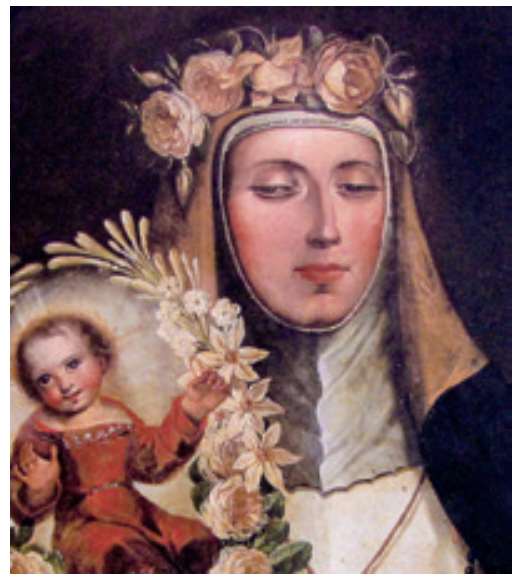

Fig. 6. Angelino Medoro (atribuido). Retrato de Santa Rosa de Lima (detalle). Óleo sobre lienzo, sin medidas disponibles, siglo XVII. Museo Catedral de Lima. Fotografía: Anthony Holguín Valdez.
La pintura en formato ovalado presenta una medida de 44 x $66 \mathrm{~cm}$, ostenta un marco de madera con ramas de acabado dorado. Generalmente para esta fecha $-y$ es una tradición adquirida por lo menos desde las primeras décadas del siglo XVIII- los marcos de los lienzos solían adornarse con hojas de laurel, por ejemplo, en el inventario de los condes de la Torre Velarde se indicó entre los muebles de sala "seis pequeños apaisados de Santos Anacoretas con sus ojas de laurel" (AGN, 1788, f. 32v). Este retrato de busto, presenta a Santa Rosa como terciaria dominica, su rostro sereno con ojos almendrados y boca pequeña están envueltos en una toca y velo blanco, dejando caer sobre sus hombros los tramos de su rosario, sobre la cabeza porta una corona de rosas y con su mano derecha sostiene un ramillete de estas flores. La imagen se ubica sobre un fondo oscuro y un halo emana 


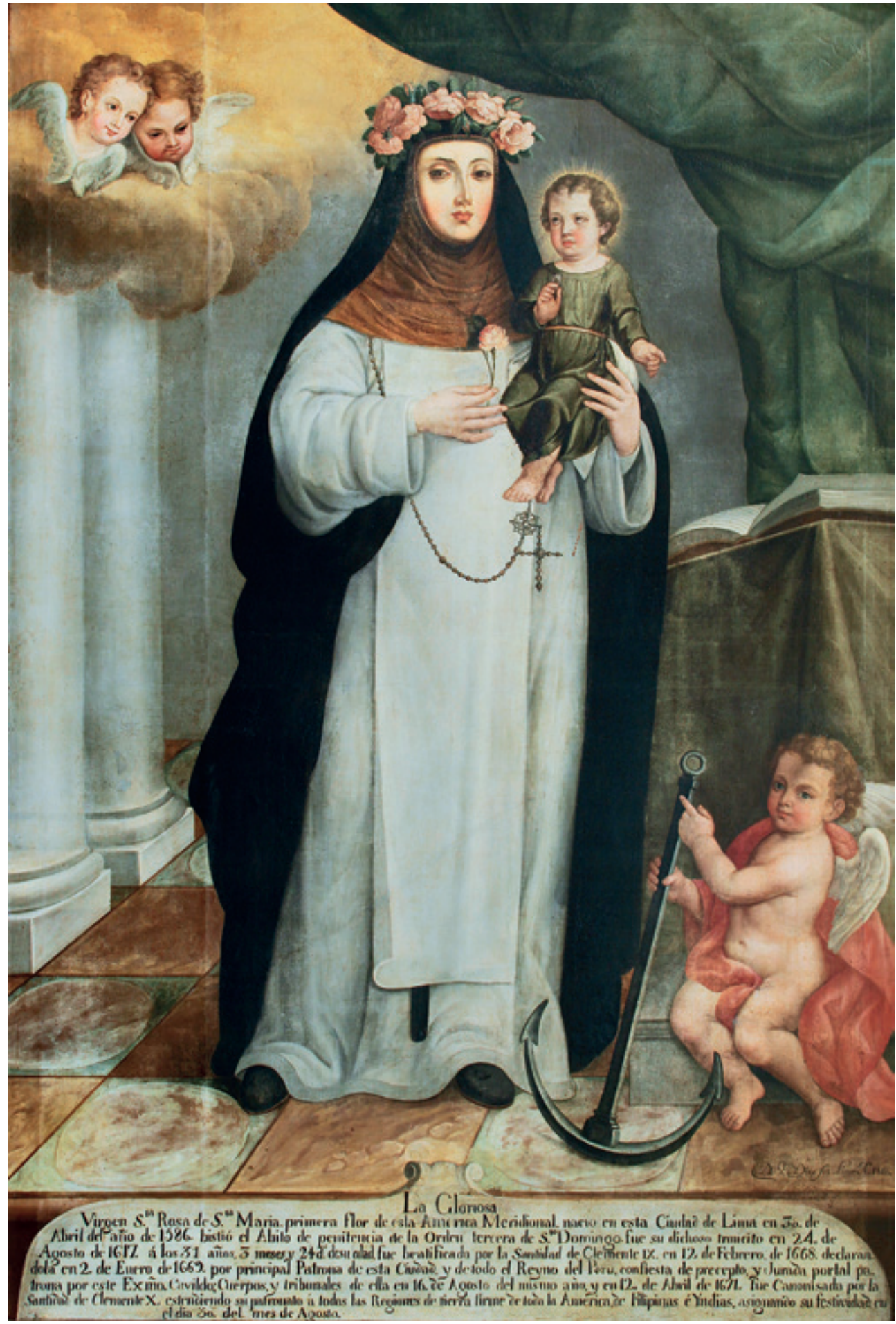

Fig. 7. Pedro Díaz. Retrato de Santa Rosa de Lima. Óleo sobre lienzo, 190 x $140 \mathrm{~cm}, 1810$. Museo Nacional de Arqueología, Antropología e Historia del Perú. Fotografía: Anthony Holguín Valdez. 
de la silueta de la santa, y pareciera seguir el patrón iconográfico de uno de sus retratos póstumo conservado en la Catedral de Lima (Fig. 6), pero a diferencia de esta última, la pintura de Díaz demuestra cierto esquematismo en la ejecución del retrato con ligeros difuminados de grises para generar volumetría al rostro. Sin embargo, el pintor manifiesta mayor virtuosismo en 1810, cuando realiza la efigie de cuerpo entero de Santa Rosa para la sala capitular del Cabildo de Lima (Fig. 7), lienzo que forma un pendant junto al retrato de San Francisco Solano, encargo realizado por el alcalde de Lima, el conde de la Vega del Ren (AGN, 1810, f. 2r). ${ }^{8}$

Nos llama la atención el esquematismo formal del retrato de Santa Rosa de Lima, al compararlo con otros ejemplos de la producción de Díaz, por ejemplo el de las efigies de vírgenes y santas ${ }^{9}$ que presentan un tipología muy particular como el uso de rostros finos de una mayor preocupación por la volumetría y naturalidad de los rasgos faciales, la boca menuda y mentón redondeado, ojos entrecerrados con cejas delineadas, la nariz recta con asa y narina curvilíneas. Por el contrario, esta pintura recurre a una simplificación de los trazos y no intenta demostrar un verismo del rostro de la santa limeña, ${ }^{10}$ en efecto, el contenido simbólico supera a la propia imagen arquetípica. Por lo tanto, la ejecución de esta obra debió realizarla un oficial del taller de Díaz (Kusunoki, p. 179) ${ }^{11}$ debido a que por entonces el maestro pintor necesitó asistencia para los numerosos encargos pictóricos que recibía. Sabemos, por ejemplo, que el canónigo Joaquín de Uztártiz contrató con Díaz para elaborar diversas pinturas al óleo de formato ovalado, entre las que se encontraba la de Santa Rosa de Lima y, además, una de Nuestra Señora de los Dolores, de San Felipe Neri, una de gran formato de Nuestra Señora de la Antigua, y aquellas "varias pinturas" entregadas a Matías Maestro y su hermano Clemente (AGN, f. 828 r; 79, f. 303r).

La iconografía de Santa Rosa de Lima fue impulsada con fuerza a principios del siglo XIX, pues junto a la imagen de San Francisco Solano, se consideraba que "ambos personajes encarnaban el pasado espiritual de la ciudad y eran invocados a menudo como parte de un discurso localista esgrimido por los defensores de la sociedad criolla" ( Buntinx \& Wuffarden, 2005, pp. 16-17). Por tal motivo, su carga política y religiosa explica la proliferación de sus imágenes en los inventarios civiles, es por ello que el pequeño retrato de Santa Rosa de Pedro Díaz responde ciertamente a su carácter devocional, que solo pudo ser albergado en espacios privados. Sabemos, por ejemplo, que "el inventario de bienes del burgalés Diego

8 El recibo de pago se lee: "Recivi del Sr. Conde de la Vega de Ren, Alcalde Ordo. de esta Ciudad, trecientos quarenta ps. del importe de dos retratos de cuerpo entero con su marcos, y coronaciones dorados; el uno de la gloriosa Patrona Sta. Rosa, y el otro del Glorioso Sn. Fco. Solano, copiados por los retratos originales, para la sala Capitular del Exmo. Cavildo de esta dha. Ciudad de Lima, en 14 de Dce. de 1810". Por otra parte, sabemos que el Museo Convento San Francisco de Lima ha puesto en exposición un retrato de San Francisco Solano, con las mismas dimensiones de la pintura que aquí estudiamos, pero no hemos podido estudiarlo in situ y determinar si es obra de Pedro Díaz.

9 Véase los ejemplos de Santa Cecilia (h. 1700, Convento de la Merced, Lima); Virgen del Carmen con el Niño (1776 y 1801, ambas en el Museo de Arte de Lima); Virgen con el Niño según modelo de Mateo Pérez de Alesio (1806, colección particular, Lima); Virgen del Rosario de Chiquinquira (1805, Parroquia de Nuestra Señora de los Desamparados y San José, Lima).

10 Para la fecha circuló muchas imágenes sobre la veru imago de Santa Rosa de Lima. Posiblemente la estampa de Marcelo Cabello titulada Verdadero Retrato de $S^{\text {ta }}$. Rosa de $S^{\text {ta }}$. Maria tuviera mayor repercusión entre la población limeña, en gran medida por su bajo costo y accesibilidad de adquirirlo.

11 En la última publicación sobre José Gil de Castro, se ha indicado la formación profesional del pintor en el taller de Pedro Díaz, esto a partir de razones estilísticas como el tratamiento de los pliegues de telas. Es probable que José Gil de Castro ejecutara el retrato por encargo del maestro Díaz, pero a falta de registros documentales que testifiquen esta hipótesis no podemos desarrollar mucho sobre el tema. Por otra parte, al oficial del taller que pintó esta obra no le estaba permitido rubricar su autoría en el lienzo, es por ello que Díaz coloca su firma junto al nombre del encargante. 
Antonio de la Casa y Piedra, efectuado en junio de 1807" (Holguín, 2019, pp.121-130), ${ }^{12}$ tuvo como parte de su colección de pinturas una lámina , así como un "bulto de barro" de Santa Rosa de Lima en el retablo de su oratorio (AGN, 1807, ff. 357v-358r.). Su difusión iconográfica, se dará con mayor fuerza desde el ámbito oficial que trató de difundirla junto a los santos peruanos, encumbrado al concepto de defensa del orden colonial, ya que el símbolo estratégico de esta Concordia Española era Rosa de Lima (Mujica, 1995, p. 190). En 1808 se inauguró el Cementerio General de Lima, con una capilla cuya bóveda fue decorada por el sevillano José del Pozo con una pintura apoteósica "de los bienaventurados Santo Toribio, Santa Rosa y San Francisco Solano". ${ }^{13}$ Por su parte el Cabildo Metropolitano encargó a Matías Maestro una serie de lienzos sobre la defensa de la iglesia limeña, en la cual se ubicó el cuadro de La Universidad de San Marcos defensora de la Escolástica, así en esta obra la presencia de Santa Rosa sería el fruto que las Indias dieron por la conquista española y, además, de emplear su imagen como protectora del orden colonial (Kusunoki, 2006, p. 202).

Ahora bien, el retrato de Santa Rosa de Lima fue un encargo del canónigo metropolitano José

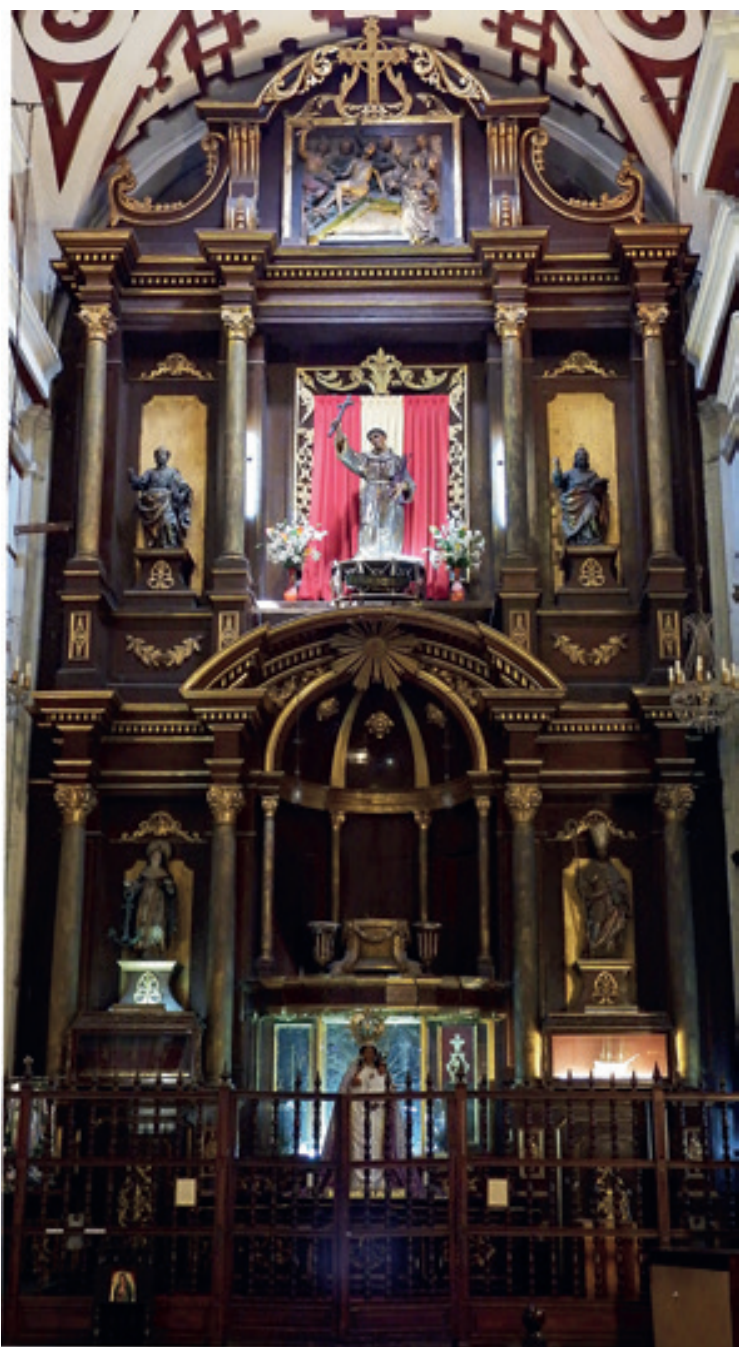

Fig. 8. Anónimo. Retablo de la hermandad de Nuestra Señora de Aranzazu. Tallado de madera y ensambladura, sin medidas disponibles, 1899. Iglesia de San Francisco de Lima. Fotografía: Anthony Holguín Valdez.

Joaquín Uztáriz y -como indicamos antes- su nombre está inscrito en el reverso del lienzo. Por lo tanto, formulamos las siguientes interrogantes: ¿quién fue José Joaquín Uztáriz? ¿Qué vínculo tuvo con Pedro Díaz? ¿Desde un principio el retrato de Santa Rosa de Lima se obsequió al convento franciscano de Lima?

12 Diego Antonio de la Casa y Piedra (1750-1806) fue un comerciante natural de Burgos, España. Activo en Lima como mercader desde 1777, llega a ser miembro de la cofradía de Nuestra Señora del Rosario de los Españoles (convento dominico de Lima) y la Hermandad de San Diego de Alcalá (convento franciscano de Lima). Desde 1795 hasta 1804 trabaja como administrador de obras de la Catedral de Lima, junto a Matías Maestro y el arzobispo Domingo González de la Reguera. Fue coleccionista de pintura devocional y contrato con varios artífices de Lima.

13 Descripción del Cementerio General, 1808, B. Fue Matías Maestro el administrador de las obras del Cementerio General y contrató a José del Pozo para esta importante decoración, por ella cobró un total de 400 pesos y llegó a finalizarlo el 15 de abril de 1808 (A. H. B. P. .L., 1807-1877, ff. 23-34). 
José Joaquín de Uztariz y el retrato de Santa Rosa de Lima

Sobre el encargante, José Joaquín Uztáriz, sabemos que fue originario de Navarra, España, hijo de Juan Bautista de Uztáriz, un importante comerciante de Cádiz que llegó a constituir una "Compañía de Comercio" mediante la asociación de los Cincos Gremios Mayores de Madrid a mediados del siglo XVIII. De esta manera la personalidad de José Joaquín sería importante, dado que actuaría como apoderado y agente de la Compañía en Lima en 1770 (Ruiz, 1983, p.33). ${ }^{14}$ Sin embargo, son pocas las noticias documentales de su trayectoria como negociante en ésta ciudad, es posible que dejara su poder a un socio del comercio hacia finales de la centuria, pues el 16 de abril de 1793 recibió el hábito sacerdotal, siendo nombrado cura de Jauja y adquiriendo la "media ración de Bueno" (Bermúdez 1903, p. 375), en adelante recibió distintos puestos hasta ser nombrado tesorero y canónigo del Cabildo Metropolitano de Lima en 1803 (Ibídem, p. 380). En la administración catedralicia José Joaquín participó del proceso de reforma artística del templo matriz que inició el arzobispo Juan Domingo González de la Reguera junto a Matías Maestro entre los años 1798 y 1806, colaborando junto a los pintores, escultores y alarifes reunidos in situ. Solo así puede explicarse el interés de Uztáriz sobre el denominado "buen gusto" de las artes y que conllevó a entablar una amistad con el propio Maestro, hecho que lo motivó a adquirir una importante colección de pintura religiosa, que se puede verificar en su testamento de 1807 (AGN, 1807, ff. 300r-304). ${ }^{15}$ Bajo este contexto Uztáriz probablemente debió conocer a Pedro Díaz, a quien encarga realizar el retrato de Santa Rosa de Lima y posiblemente otras tantas pinturas que luego dejaría en posesión de su albacea.

Ahora bien, ¿cómo llegó el retrato de Santa Rosa de Pedro Díaz al convento franciscano de Lima? Pues a partir de una de las cláusulas del testamento de Uztáriz. En la décima octavo estipulación se declara: "á Don Martín de Osambela le dejo un ovalo pequeño de la Ymagen de Nra. Patrona Sta. Rosa en acción de gracias, por lo que contribuye al desempeño de mis ultimas disipaciones" (Íbidem, f. 302v). De esta manera, al fallecer Uztáriz el retrato de la santa limeña pasó a los bienes de Martín de Osambela, un reconocido comerciante navarro activo en Lima desde 1775 (Hampe, 2001), cuya cercanía a la orden seráfica está comprobada en su testamento de 1812 en donde pide ser amortajado con el hábito y cuerda de la orden de San Francisco, manifiesta además, su pertenencia como devoto a la hermandad de Nuestra Señora de Aranzazu propia de los inmigrantes vascos (AGN, 1812, f. 83v), de tal forma que el retrato terminó ubicado en el interior de la iglesia franciscana (Fig. 8). Por consiguiente, podemos declarar que Osambela otorgó en calidad de donación el retrato de Santa Rosa para dicha hermandad de Aranzazu, en una orden que debió efectuar en su último testamento de 21 de febrero de 1822 (AGN, 1822, f. 45v).

Por lo tanto, el retrato de la santa limeña estuvo en posesión de dos propietarios; el primero, José Joaquín de Uztáriz; y el segundo, Martín de Osambela. En definitiva la conservación de la pintura hasta la actualidad se debe en parte al cuidado que le otorgó la hermandad de Aranzazu durante todo el periodo decimonónico y su posterior traslado a la colección general de piezas artísticas del convento franciscano, almacenadas en las celdas del claustro principal durante la primera mitad del siglo XX.

Creemos que este lienzo de Pedro Díaz es importante en tanto su contenido formal e iconográfico, por otro lado, la inclusión del nombre del propietario y la fecha en el reverso del lienzo, nos ayudaron a desarrollar el contexto en la cual esta obra fue elaborada, pues es rara la presencia del encargante en este género de pinturas.

14 Asimismo, en abril de 1768 José Joaquín en compañía de sus socios Nicolás de Roxas y Juan Felipe de Uztariz, entablaron negocios con la condesa de Vista Florida, en Lima (AGN, Orencio Ascarrunz, protocolo 83, 1768, f.923v).

15 En la cláusula décimo novena del testamento se indica: "Ytem á Don Matías Maestro y á su hermano Don Clemente/ les dejo varias pinturas que ya le tengo entregadas en señal/ de amistad". 


\section{Referencias bibliográficas}

Archivo General de la Nación (AGN). CA-GC 1, legajo 21, documento 274, f. 2r.

Archivo General de la Nación (AGN). Carlos Josef Castilla, protocolo 186, 1788, f. 32v.

Archivo General de la Nación (AGN). Carlos Josef Castilla, protocolo 186, 1793-1794, ff. 326v, $447 \mathrm{r}, 568 \mathrm{v}$.

Archivo General de la Nación (AGN). EstancosAdministrativos, legajo 19, documento 234, 2507-1793, f. 3r.

Archivo General de la Nación (AGN). Francisco Munarris, protocolo 450, 1807, ff. 357v-358r.

Archivo General de la Nación (AGN). Gaspar Salas, protocolo 664, 26-05-1812, f. 83v.

Archivo General de la Nación (AGN). Gaspar Salas, protocolo 669, 21-02-1822, f. 45v.

Archivo General de la Nación (AGN). Miguel Antonio de Arana, protocolo 77, f. 828r; 79, f. 303r.

Archivo General de la Nación (AGN). Miguel Antonio de Arana, protocolo 79, 1807, ff. 300r-304.

Archivo General de la Nación (AGN). Juzgado de cofradías, leg.17, cuad.472, 1815, fol.6v y 7r.

Archivo General de la Nación (AGN). Superior Gobierno, legajo 19, cuaderno 519, 21-06-1788, ff. $9 v$ y $10 \mathrm{r}$.

Archivo Histórico de Beneficencia Pública de Lima (AHBPL). Protocolo de documento del Cementerio General de Lima, 1807-1877, ff. 23-34.

Alcalá, L. "La pintura en los virreinatos americanos: planteamientos teóricos y coordenadas históricas". En L. Alcalá \& J. Brown (Eds.), Pintura en Hispanoamérica. 1550-1820. Madrid: Ediciones el Viso \& Fomento Cultural Banamex, 2014.

Bermudez, J. Anales de la Catedral de Lima, 1534 á 1824. Lima: Imprenta del Estado, 1903.

Buntinx, G. y Wuffarden, L. "Pinacoteca Municipal Ignacio Merino. Historia de un legado". En Pinacoteca Municipal Ignacio Merino. LXXX Aniversario. 1925-2005. Lima: Municipalidad Metropolitana de Lima, 2005.

Esquivel, O. Un retrato de Bolívar. Estudio introductorio de la obra de Pablo Roxas. Lima: Seminario de Historia Rural Andina, Universidad Nacional Mayor de San Marcos, 2015.

Flores Araoz, J. Santa Rosa de Lima y su tiempo. Lima: Banco de Crédito del Perú, p. 230, 1995.

Flores Galindo, A. Aristocracia y plebe. Lima 176017830. Lima: Mosca Azul, 1984.
Hampe, T. "Don Martín de Osambela, comerciante navarro de los siglos XVIII/ XIX, y su descendencia en el Perú”. En Anuario de Estudios Americanos, Vol. 58, n. ${ }^{\circ} 1,2001$.

Holguín, A. Los lienzos de San Diego de Alcalá de José María del Pozo y Téxada. El último pincel del barroco sevillano en el epílogo virreinal (Tesis para optar el título de Licenciatura en Arte). Universidad Nacional Mayor de San Marcos, Lima, 2019.

Kusunoki, R. "Matías Maestro, José del Pozo y el arte en Lima a inicios del siglo XIX". En Fronteras de la Historia, $\mathrm{N}^{\circ}$ 11, 2006.

Kusunoki, R. y Wuffarden, L. "Un retratista limeño en la era de la Independencia". En N. Majluf (Ed.), José Gil de Castro. Pintor de libertadores. Lima: Asociación Museo Arte de Lima, 2014.

Majluf, N. "En busca de José Gil de Castro. Rastros de una (auto) biografía". En N. Majluf (Ed.), José Gil de Castro. Pintor de libertadores . Lima: Asociación Museo Arte de Lima, 2014.

Mujica, R. "El ancla de Rosa de Lima: Mística y política en torno a la Patrona de América". En Flores Araoz (Ed.), Santa Rosa de Lima y su tiempo. Lima: Banco de Crédito del Perú, 1995.

Ruiz, J. "Rasgos de modernidad en la estrategia comercial de los Uztáriz, 1766-1773”. En Revista Temas Americanistas. №. 3, 1983.

S/A. Descripcion del Cementerio General mandado erigir en la Ciudad de Lima, por el Exc. Señor Don Jose Fernando de Abascal y Sousa, Virrey, y capitán general del Perú. Lima: Casa Real de Niños Expósitos, 1808.

Wuffarden, L. "Ilustración versus tradiciones locales, 1750-1825”. En L. Alcalá \& J. Brown (Eds.), Pintura en Hispanoamérica. 1550-1820. Madrid: Ediciones el Viso \& Fomento Cultural Banamex, 2014.

Recibido el 30 de marzo del 2019 Aceptado el 17 de septiembre del 2019 